\title{
Manual de Introducción a las Comunidades Virtuales.
}

Pau Ferri Aracil. 
El concepto de comunidad virtual

Una comunidad virtual es un sitio de Internet donde un conjunto de personas comparten los mismos intereses y necesidades. En él se da una interacción y comunicación entre los miembros, y la vinculación de los miembros con su comunidad virtual.

Ciertas características que presentan la mayoría de las comunidades virtuales:

- Los miembros se sienten parte de una totalidad social amplia. Existe una red de relaciones entre sus miembros. Hay una corriente de intercambio de contenidos que tienen valor para sus miembros. Las relaciones entre los miembros se mantienen en el tiempo.

- Responden a necesidades: a) un interés u objetivo común a otras personas; b) el deseo de compartir una experiencia o establecer relaciones sociales o comerciales; $c$ ) el deseo de disfrutar de experiencias gratificantes; d) la necesidad de realizar transacciones de diversa índole.

- Facilitan el acceso a información segmentada: La CV recopila la mejor información existente en la red del tema sobre el que versa la comunidad. Para ello, cada comunidad reúne estudios, trabajos, artículos, webs de empresas del sector, productos o servicios.

- Facilitan la comunicación: adquisición e intercambio de conocimientos en temas determinados; establecimiento de relaciones personales con personas de intereses afines; reconocimiento del trabajo intelectual por un grupo social.

El interés de las empresas en las Comunidades Virtuales comienza a activarse seriamente al constatar su valor comercial, además de permitir el establecimiento de estrategias de marketing altamente segmentadas. Permiten obtener datos sobre los clientes y utilizarlos apropiadamente para obtener valor comercial y para utilizar la información que se consigue para proporcionar más valor a los mismos clientes.

Son agentes de desarrollo organizacional y creadoras de valor, tanto para la empresa como para sus clientes y permiten diferenciarse de la competencia. Son un poderoso factor de fidelización hacia una empresa y sus productos, siendo generadoras de beneficios. Además, permiten responder a la necesidad de incorporar a proveedores y consumidores a los procesos de una empresa y hacerlos participar en la concepción, producción y distribución de sus productos y servicios.

Las empresas desean crear comunidades virtuales porque:

- Facilitan la fidelización de clientes y la diferenciación en los mercados competitivos.

- Son auto-generadoras de contenidos y la actualización y mantenimiento no requieren grandes inversiones.

- Permiten la segmentación de los clientes y del mercado.

- Se promocionan mediante el "boca-oreja", produciendo una mayor retroalimentación por parte de los clientes sobre los productos y servicios.

- Facilitan el acceso a información sobre las necesidades del cliente, con lo cual, los proveedores pueden diseñar mejores productos y servicios.

- Son generadoras de masas críticas de usuarios, que a su vez determinan el atractivo para otros ofertantes de productos y servicios complementarios, mediante acuerdos y alianzas.

- La evolución y mantenimiento en el tiempo de las relaciones personales y comerciales entre los miembros, se traduce en una lealtad y confianza hacia el promotor de la Comunidad.

- Permiten segmentar el mercado en clientes de uno en uno, haciendo percibir a este cliente una oferta absolutamente personalizada y única, lo que implica su fidelización, y la creación de valor mutuo.

- La publicidad deja de ser intrusiva. Esto permite tener clientes potenciales realmente interesados en los productos y servicios que estamos ofreciendo. 


\section{Servicios dentro de una comunidad virtual}

La comunicación directa, activa, entre todos los participantes en una comunidad es el objetivo declarado de un sitio web. Toda forma de reacción o retroalimentación entre los miembros y los creadores del sitio favorece la aceptación de la oferta global y su fidelidad. Aquí el visitante decide si se acomoda a un "hogar" relacionado con su tema, en el cual, además de la suscripción pasiva a informaciones de alto valor, existe un intercambio activo de ideas, opiniones o puntos de controversia.

Los foros de noticias y de chat suelen ser el punto neurálgico de la comunicación para la mayoría de las comunidades. Aquí se comunican grupos de mayor o menor tamaño y se establecen contactos con personas de intereses similares o con socios (comerciales) en potencia. La mera facilitación de estos módulos da lugar, en muchos sitios web, a enormes cifras de visitantes y a una discusión activa, en parte también controvertida, sobre casi todos los ámbitos de la vida privada y laboral del ser humano. El diálogo activo entre visitantes y miembros de una comunidad tiene que ser uno de los objetivos más importantes para los gestores del sitio.

A la hora de elegir y de incluir las funciones de diálogo se ha de procurar básicamente que dominen dos formas distintas de comunicación:

- comunicación asíncrona (con desplazamiento temporal), como por ejemplo el correo electrónico o foros.

- comunicación sincrónica (simultánea), como por ejemplo el chat.

\section{Cuadro sinóptico de herramientas de diálogo y comunicaciones}

\begin{tabular}{|l|l|}
\hline Herramientas de comunicación & Ámbitos de aplicación más importantes \\
\hline Tablones de mensajes/Libros de visitas & $\begin{array}{l}\text { Expresiones espontáneas de opinión sin la "presión" de } \\
\text { tener que participar inmediatamente en una discusión: } \\
\text { informan sobre el estado de ánimo general. }\end{array}$ \\
\hline Foro de chat & $\begin{array}{l}\text { Encuentro espontáneo con personas de inclinaciones } \\
\text { afines. Muy dependiente de la cifra de participantes. Los } \\
\text { visitantes tienen que estar activos simultáneamente en la } \\
\text { página. Puede tener lugar en momentos determinados, } \\
\text { acordados. }\end{array}$ \\
\hline Archivo de chat & $\begin{array}{l}\text { Almacenamiento o "grabación" de todos los chats } \\
\text { moderados, para información de otros miembros }\end{array}$ \\
\hline Foros de correo electrónico/Tablones de & $\begin{array}{l}\text { En muchas comunidades son el centro de comunicación } \\
\text { entre los miembros. Iniciación individual, en cualquier } \\
\text { momento, en una o varias temáticas. Visión global sobre } \\
\text { opiniones controvertidas. }\end{array}$ \\
\hline Listas de correo & $\begin{array}{l}\text { Discusión entre varios participantes sólo a través del } \\
\text { correo electrónico. }\end{array}$ \\
\hline Correo electrónico & $\begin{array}{l}\text { Conversación individual, no pública, de miembros entre sí } \\
\text { o bien con el administrador de la comunidad. }\end{array}$ \\
\hline Servicios buscapersonas/SMS & Envío de informaciones desde el sitio web a móviles. \\
\hline Mensajería instantánea & $\begin{array}{l}\text { Contacto espontáneo, individual, en tiempo real y similar al } \\
\text { chat: se puede dirigir en el sitio de forma intencional a } \\
\text { personas de inclinaciones afines. }\end{array}$ \\
\hline
\end{tabular}

Para que una comunidad sea completa debería de contener un registro de usuarios: 


\section{Registro de Usuario}

El registro de usuario cumple la función de mantener al conjunto de usuarios registrados dentro del entorno, así como darles acceso a los diferentes sistemas o servicios (páginas) en función de su nivel de acceso o características adicionales incorporadas en el mismo perfil de usuario.

El perfil de usuario, según los datos introducidos por él mismo, o bien desde el lado de administración, contiene aquellos campos, públicos o privados, que se decidan desde la administración. Las funcionalidades básicas son:

- Definición y creación de la base de datos: número de campos, tipo de los campos (numérico, texto, memo, lógico o fecha), longitud, campos públicos o privados

- Modificación de la Base de Datos online

- Encriptación del password

- Asignación automática de niveles de acceso

- Persistencia de sesión entre diferentes herramientas durante la sesión activa

- Integración con sistemas externos

- Creación de índices de bases de datos específicos para optimizar el rendimiento

- Copia de seguridad

\section{Facilidad para la navegación}

Los usuarios registrados con su login y password encuentran todos los formularios precumplimentados con sus datos, de forma que los pueden modificar (para colocar otro nombre o e-mail).

\section{Niveles de Acceso}

Desde el entorno de administración se definen las áreas, elementos o módulos disponibles a los usuarios, basándose en el nivel de los mismos (preasignado en el entorno de administración).

Pueden utilizarse para definir las prioridades de un usuario no sólo el nivel de acceso sino también otros campos del entorno de registro.

\section{Quién está online}

Permite conocer qué número de usuarios registrados (cantidad) está conectados al entorno en cada momento. Al hacer clic en el enlace que indica el número de usuarios es opcional que aparezca la lista de los mismos, y sobre el nick (login seleccionado por el usuario) un enlace a su perfil público.

\section{Herramientas de Usuario}

\section{Perfil de Usuario}

El registro básico de usuario incorpora datos básicos del mismo necesarios para la navegación y participación en el entorno como usuario identificado.

Los perfiles de usuario permiten a éste disponer de fichas propias (en función de la definición del administrador) para compartir sus datos con otros usuarios.

Modelos de perfil podrían ser el curriculum vitae, una ficha de empresa, gustos o preferencias personales, etcétera.

Los usuarios pueden realizar acciones sobre sus perfiles como: 
- Darlo de alta, editarlo o borrarlo

- Hacerlo público o privado

- Añadirlo a anuncios, postales digitales, etcétera

- Asignar una contraseña para permitir ver un perfil privado determinado a ciertos usuarios

\section{Mensajería online}

Un usuario registrado dispone de una lista de usuarios a la que puede añadir nuevos usuarios, o darlos de baja. Una vez añadidos puede enviarles mensajes que, si el otro usuario está online recibirá de forma inmediata, o bien, si el usuario no está online quedarán en su carpeta de recepción de mensajes.

El usuario puede ignorar los mensajes que le envía un usuario específico de forma genérica, sea cual sea el contenido del mensaje.

Esta mensajería online permite mantener el anonimato de las cuentas de correo y así lograr que los usuarios sólo hagan público su nick o identificador de usuario.

\section{Calendario Personal}

El calendario personal en entorno web permite al usuario mantener un seguimiento de sus citas o recordatorios. Las características del calendario son:

- Tiene múltiples categorías creadas y administradas por el mismo usuario

- Las categorías pueden tener dos niveles de protección: para visualizar o para añadir eventos. Un usuario puede disponer de una serie de categorías públicas dónde el resto de usuarios añade entradas, y a la vez disponer de otras dónde sólo los usuarios conocedores de la contraseña pueden eliminar o añadir entradas, y por otro lado una contraseña que les permita o no la visualización.

- Puede ser compartido con otros usuarios o individual. Puede bloquearse totalmente el calendario de modo que ningún usuario pueda visualizarlo ni añadir entradas o, también de forma general, permitir entradas anónimas (sin nombre de usuario ni e-mail).

- Se coordina con las Comunidades No Moderadas.

- Se coordina con el entorno de eventos del site. Si se tiene instalada la herramienta de calendario, desde los eventos del Site puede añadir con sólo un clic esos eventos a su calendario.

- El usuario tiene completo control del diseño de la visualización.

\section{Páginas Propias de Usuario}

Páginas asociadas a cada usuario, administradas por él mismo y puestas de forma libre para su navegación dentro del portal.

El conjunto de estas páginas crea un entorno de Ciudad Virtual cuyo modelo conocido más popular es Geocities.

Las características comunes a la mayoría de páginas de usuario son:

- Tabla de contenidos

- Buscador interno

- Gestor de imágenes propias

- Gestor de banners propio

- Lista de servicios

- Páginas de soporte a los servicios

- Censor de palabras no aceptadas

- Definición de colores y tipos de letra globales del entorno 
Permite al usuario añadir tareas pendientes a una lista propia que se visualiza en diferentes formatos en función de su nivel de prioridad y estado.

Permite:

- Definir y cambiar prioridad de las tareas

- Cambiar estado: en curso, por iniciar o finalizadas

- Ordenar por fecha

- Comentarios por enlace

\section{Lista de Favoritos}

Lista de enlaces preferidos añadidos por el usuario a una lista propia.

Permite:

- Administración de favoritos (añadir, borrar, etcétera)

- Creación de categorías para la clasificación de dichos enlaces

- Control de diseño del entorno por parte del usuario: título, colores, etcétera

\section{Álbum de fotos}

Entorno para disponer de imágenes propias de los usuarios clasificadas en el servidor de acuerdo con las preferencias del usuario.

Permite:

- Ser compartido o no con otros usuarios por categorías

- Lista de ficheros

- Creación de categorías, públicas o privadas

- Publicación de ficheros

- Aceptación previa de publicación por parte de otros usuarios

\section{Álbum de Ficheros}

Bajo la misma filosofía del álbum de fotos y con las mismas funcionalidades, permite a los usuarios subir todo tipo de ficheros. Si los ficheros permiten visualizarse desde el entorno web (Word, Adobe, Excel,...) estos se abren desde la misma localización. Dispone de las mismas funcionalidades que el álbum de fotos.

\section{Recomendaciones}

Módulo orientado a permitir que el usuario recomiende el entorno web a otros usuarios mediante el envío automático de un e-mail.

- Permite disponer de un registro de todos los e-mails enviados

- Personalización del e-mail enviado por parte del Administrador

- Asocia el módulo a una página concreta de modo que no pueda ser accesible desde el exterior y producir spam (correo no deseado).

- Tiempo de espera mínimo para el envío de un nuevo e-mail (protección contra spam)

\section{Foros}

\section{Foros Moderados}

Los foros moderados son un entorno de foro administrado internamente que permite a los usuarios enviar y leer mensajes publicados directamente en web. 
- No requieren registro en el foro en cuestión (aunque sí pueden requerirlo en el portal)

- Puede haber diversas categorías en cada foro.

- Tienen una lista de correo asociada a cada categoría. El usuario puede suscribirse para recibir los nuevos mensajes enviados a esa categoría por mail.

\section{Foros No Moderados}

Los foros no moderados son aquellos creados libremente por los usuarios.

Para que el usuario pueda entrar en la comunidad es necesario que esté registrado en el entorno general, dejando luego a discreción del administrador la necesidad de que el usuario se encuentre registrado en la comunidad para poder enviar mensajes o verlos.

Una vez creados disponen de una serie de herramientas, muchas de las cuales se han especificado ya en sus funcionalidades en el ámbito de usuario, y que aquí amplían su capacidad para permitir su uso a nivel de comunidad. Los elementos de los cuales consta una comunidad son:

- Los usuarios registrados en la comunidad pueden asociar una URL a su registro que aparecerá en todos los mensajes que envíen.

- Foro

- Álbum de fotos

- Lista de usuarios registrados. Los administradores del Foro se resaltan en la lista.

- Enlaces

- Calendario de la comunidad

- Tablón de Anuncios

A nivel administrador (creador) del foro, se tienen diferentes opciones:

- Cambiar colores y diseño general de la comunidad

- Permitir a otros usuarios dar soporte a la administración

- Cambiar las palabras clave de la comunidad para incluirlas en el buscador interno y otros buscadores.

- Permitir invitados a la comunidad (pueden ver pero no enviar mensajes ni participar de otra forma)

- Prohibir la entrada de usuarios a la comunidad

- Entorno de censor personalizado para los mensajes enviados al foro

- Incluir una foto y texto de entrada a la comunidad

Una vez creada la comunidad, en su barra de herramientas al administrador le aparece el enlace para ir de forma directa a la administración.

Del mismo modo, los usuarios suscritos a la comunidad virtual disponen sus propios enlaces para enlazar directamente con las mismas, además de un entorno desde el cual abandonar la comunidad.

\section{Listas de correo}

La lista de correo consiste en un entorno que permite que los usuarios, tras suscribirse a dicha lista, reciban de forma automática los correos preparados por un administrador de la lista.

El administrador de la lista tiene diferentes opciones de administración:

- Definir el formulario de suscripción (qué campos tiene y si son obligatorios u opcionales)

- Modo de suscripción: con o sin confirmación del usuario. Si se elige con confirmación el usuario, tras suscribirse recibe un e-mail solicitándole que haga clic en un enlace para 
confirmar su suscripción. Está orientado a evitar spam por suscripción de terceros. Los usuarios tienen 2 días para confirmar su suscripción.

- Definir los colores del formulario de suscripción a la lista de correo

- Guardar los e-mails enviados

- Reenviar e-mails enviados

- Enviar e-mails a usuarios suscritos desde una fecha determinada

- Búsquedas sobre la base de datos

- Copias de seguridad

- Importación de bases de datos externas

- Unir el formulario de suscripción a cualquier página, interna o externa al entorno digital donde se crea el formulario.

- Configurar las cuentas de correo, servidores, contraseña, etcétera

- Configurar los modos de envío y tiempos de espera

\section{Contenidos}

\section{Eventos}

Eventos de interés clasificados por fecha, tipo, zona geográfica y categoría para la navegación por parte de los usuarios.

Sus funcionalidades son:

- Clasificación de eventos por meses o zonas geográficas

- Buscador entre los eventos

- Categorías de eventos

- Tipos de Eventos

- Resalte de ciertos eventos.

- Incorporación directa de los eventos al calendario personal del usuario, y enlace a la página con la descripción del evento.

- Enlace desde el evento a la contratación o reserva del mismo

\section{Encuestas}

Hay dos tipos de entornos de encuestas disponibles:

- Módulo gráfico lateral de encuesta. Son encuestas diseñadas para obtener una respuesta rápida y ser cambiadas con relativa frecuencia. Una vez que el usuario ha votado no puede volver a votar en esa encuesta y el resultado, en forma de barras gráficas y porcentaje, así como número de votos totales, aparece en el lateral.

- Entorno permanente de encuestas. Este entorno está orientado a mantener encuestas bajo diferentes categorías y durante más tiempo. Genera las encuestas clasificadas en el nivel de entorno de encuestas (por ejemplo, tecnología, salud o política) y dentro de cada entorno es posible crear tantas encuestas como se requiera.

Cada encuesta tiene una fecha de inicio y final, y tiene tantas opciones de voto (respuestas) como el administrador decida.

Una vez que una encuesta se ha cerrado es posible volver a abrirla, desactivarla (no está visible) o borrarla.

Cada encuesta puede disponer de un texto inicial de explicación tan largo como sea necesario o bien enlazarse con otras páginas web.

\section{Contenidos}


El gestor de contenidos permite introducir noticias propias o internas en el entorno. Estas noticias o contenidos (textos en formato HTML con imágenes o si éstas), desde el punto de vista del administrador del artículo permite:

- Añadir, editar o borrar artículos

- Definir si un artículo se encuentra activo, inactivo o en revisión

- Seleccionar fecha de publicación

- Definir categorías para los contenidos. Aún estando definidas una serie de categorías es posible incorporar noticias bajo una categoría adicional

- Definir imágenes por categorías. Aún existiendo una serie de imágenes predefinidas es posible asignar imágenes adicionales al artículo.

- Definir referencias a los artículos de forma estándar

- Definir las meta tags del artículo y añadirlo al buscador de contenidos

El administrador puede (además de gestionar el diseño):

- Replicar el entorno para gestionar diferentes entornos de contenidos

- Definir si los contenidos tienen o no un foro asociado, referencias etcétera

- Definir las diferentes vistas del artículo (para impresión, WAP, e-mail, etcétera)

- Gestionar el flujo de trabajo para cada usuario coadministrador de los contenidos: quién puede añadir, revisar, borrar artículos, categorías y referencias, y en qué categorías.

- Definir cómo aparecerán los artículos en la página general: titulares, resumen, con imagen, con comentarios, etcétera

Los usuarios finales, si las opciones correspondientes están activadas, pueden navegar por los artículos desde diferentes vistas:

- A través del buscador

- Por categorías

- Por noticias más comentadas

Además, pueden publicar comentarios a los artículos si el administrador general permite dicha opción.

Los usuarios pueden tener una vista simple del artículo para imprimirla o bien pueden enviar por mail dicho artículo a otro usuario.

\section{Buscador}

El buscador es una herramienta simple que se utiliza en las comunidades virtuales, en los artículos, etcétera.

La herramienta extrae de las páginas web la información necesaria para incorporarlas a la base de datos.

Para incorporar nuevas páginas sólo es necesario indicar la URL y la información se extrae y añade (después de la aceptación del administrador general del buscador) de forma automática.

Las funcionalidades básicas son:

- Extracción automática de la información de la página.

- Actualización de la información si la URL ya está añadida

- Si son páginas de la misma URL, clasificación bajo la misma URL

- Administración interna para clasificar por categorías y subcategorías

- Entorno de comentarios de los usuarios

\section{Gestor de Formularios}

Los entorno digitales suelen disponer de varios formularios, que una vez cumplimentados son enviados a un administrador por e-mail para su contestación, archivado, etcétera. 
Para agilizar la incorporación de dichos formularios, el sistema incorpora un gestor con las siguientes funcionalidades:

- $\quad$ No requiere conocimientos técnicos (sólo HTML) para el diseño del formulario.

- Lectura de formularios prediseñados para añadir al sistema.

- Control de errores en la cumplimentación de los formularios (e-mail, formato numérico, formato IP...)

- Definición del tipo de datos

- Envío automático a múltiples cuentas de correo

- Generación de históricos en fichero en servidor

- Página de notificación de error en la cumplimentación propia o definida por el administrador.

- Gestión de la estructura del e-mail (para su lectura automática por entornos CRM o programas de lectura y clasificación automática de e-mail)

- Auto envío de retorno al Site de dónde proviene el usuario.

\section{Gestor de Publicidad}

El gestor de publicidad mantiene módulos donde van cambiando las imágenes que aparecen en los mismos y asociándolas con una página en su enlace.

Pueden ser utilizados como entornos de publicidad habitual, o bien usados como elementos de promoción interna.

- Permite diferentes tamaños de banner

- Es autoreplicable

- Permite la gestión independiente de los diferentes espacios de banner

- Da acceso a una página de cliente con estadísticas: apariciones realizadas del banner, clics realizados (CPM)

- Calcula estadísticas sobre el CPM por IP y fecha

- Los clientes del entorno pueden administrar de forma directa sus propios banners a través de un código de cliente y contraseña asignados

El módulo de estadísticas avanzadas le permite ver, sobre los clics producidos, una agrupación de los mismos por IP, por fecha o por la web a dónde se trasladaron los usuarios.

\section{Comunicaciones Breves}

Las noticias internas están diseñadas como un pequeño módulo en el cual se comunican de brevemente las nuevas versiones o servicios que se vayan aportando al entorno digital. Su objetivo básico es la comunicación.

Dicho modulo está diseñado para publicar de forma simple textos breves en una zona lateral o en algún apartado breve del site y permita mantener a los usuarios registrados informados, 0 bien usarlo para poner enlaces a encuestas de opinión o áreas de interés.

\section{Servicios Complementarios}

\section{Estos servicios son complementarios}

- Postales Digitales: Las Postales Digitales generan un volumen importante de páginas servidas en el site al permitir que los usuarios envíen una felicitación, un recordatorio, o cualquier otro tipo de mensaje asociándolo a una imagen con un diseño de presentación personalizado. Este servicio está reconocido como uno de los más usados, ya que favorece un gran nivel de interactividad y una manera informal de comunicarse. 
Para el Site supone un servicio de valor añadido para los usuarios y una importante herramienta de marketing ya que los receptores de la postal visitan el entorno original para poder visualizar la postal que se les ha enviado.

- Anuncios Clasificados: El Servicio de Anuncios Clasificados provee un entorno corporativo para que los usuarios publiquen sus ofertas o demandas encuadradas dentro de múltiples categorías y subcategorías. Siendo este un servicio totalmente personalizado por el propietario de la web, los usuarios no tienen la percepción de estar fuera de dicho entorno, manteniendo su imagen corporativa, pero obtienen todas las ventajas en cuanto a múltiples contenidos e impacto de su anuncio, que está visible para otros usuarios en múltiples entornos web.

Tipos de Comunidades

\section{Comunidades virtuales de interés}

Son comunidades compuestas por decenas, cientos o miles de personas que desean intercambiar información relacionada con algún tema específico, este tema puede ser sobre religión, alguna enfermedad, política, algún aspecto de programación etc.. La comunicación en estas comunidades se da a través de chats, foros o listas de distribución.

En España Redlris proporciona un servicio para albergar comunidades virtuales de este tipo, la perspectiva de RedIris es: ..." CVUs (comunidades virtuales de usuario) son colectivos científicos, académicos o profesionales cuyos miembros se encuentran dispersos instituciones de RedIRIS o en en otras externas de carácter nacional o internacional (fundamentalmente Latinoamerica) pero unidos por unos intereses temáticos comunes. .."

Los servicios que ofrece la Redlris son:

- Intercambio de información sincrono y/o asincrono en formato texto y/o multimedia entre el grupo.

- Creación de bases de datos de recursos.

- Zonas de almacenamiento de información públicas y privadas. (BSCW- Basic Support Cooperative Work-)

- Aplicaciones para desarrollar proyectos o actividades.

- Creación de revistas electrónicas.

- Organización de Congresos Virtuales

Ejemplo de estas comunidades son:

Comunidades dentro del servicio Redlris (http://www.rediris.es/cvu/buscar/)

\begin{tabular}{|l|l|}
\hline$\underline{\text { http://entomologia.rediris.es }}$ & $\begin{array}{l}\text { Colectivo de usuarios que su tema principal es la } \\
\text { entomología. }\end{array}$ \\
\hline$\underline{\text { http://farmatoxi.rediris.es }}$ & $\begin{array}{l}\text { Formada por un colectivo que tiene en común su perfil } \\
\text { académico o científico relacionado con la Farmacología } \\
\text { o la Toxicología, y que utiliza diversos recursos } \\
\text { tecnológicos de la Red IRIS para coordinarse, colaborar y } \\
\text { publicar sus trabajos. }\end{array}$ \\
\hline$\underline{\text { http://neurologia.rediris.es/neurologia }}$ & $\begin{array}{l}\text { Grupo de profesionales interesados en las posibilidades } \\
\text { que ofrece la red a la hora de la comunicación científica } \\
\text { en todos los ámbitos relacionados con la neurología } \\
\text { clínica. }\end{array}$ \\
\hline
\end{tabular}




\begin{tabular}{|l|l|}
\hline$\underline{\text { http://cdeporte.rediris.es }}$ & $\begin{array}{l}\text { Comunidad creada por personas de cada una de las } \\
\text { especializaciones del deporte. }\end{array}$ \\
\hline
\end{tabular}

\section{Comunidades dentro de una Organización}

Cada vez más, las organizaciones grandes y pequeñas establecen sistemas de comunicación internos - intranets - que aprovechan la tecnología de Internet para facilitar la comunicación entre los individuos de la misma organización, algunas plataformas ayudan a entablar está clase de comunicación interna, por ejemplo Lotus Notes u otros como por ejemplo WebCT, FirstClass, etc., si se tratan de organizaciones de enseñanza (estos últimos serán vistos más adelante).

Los temas que se tratan dentro de este tipo de comunidad son referentes a la propia empresa, negocio u organización (oficialmente, aunque a veces se puede dar de temas personales), esta comunicación se da principalmente a través de listas de distribución.

En caso de ser en una organización de enseñanza la comunicación se da principalmente a través de listas de distribución, foros de discusión, tablón de anuncios y algunas veces en chats.

Para estas comunidades no se pueden poner ejemplos ya que son Intranets y solo se ven dentro de la organización, sobre las educativas se hablará más adelante.

\section{Comunidades locales on-line}

Estas comunidades están compuestas por personas de una misma ciudad, un mismo pueblo, vecinos de una misma calle, etc. que entablan conversaciones a través de la comunidad para reflejar su situación real.

Estas comunidades, algunas veces se les llama redes ciudadanas tienen como principal objetivo entablar la comunicación entre sus miembros y promover la cooperación y el intercambio entre la organización.

Por ejemplo en las redes ciudadanas de Barcelona se promueve el acceso a bajo coste a Internet entre los vecinos de los diferentes barrios (Raval, Gràcia, NouBarris, Sants), la creación de páginas web, directorio de servicios y guías de recursos de los distritos, agendas de eventos de los barrios, etc.

Algunos ejemplos de estas comunidades son:

\begin{tabular}{|l|l|}
\hline http://www.vallesnet.org & $\begin{array}{l}\text { Vallesnet es para los residentes del valles, ofrece servicios de } \\
\text { comunicación como: } \\
\text { chat, } \\
\text { - listas de distribución, mail. }\end{array}$ \\
\hline http://www.ravalnet.org & $\begin{array}{l}\text { RavalNet está orientada a los vecino que viven en el barrio del Raval de } \\
\text { Barcelona, su comunicación se da principalmente a través de: } \\
\text { foros de discusión, } \\
\text { listas de distribución y mail } \\
\text { chat } \\
\text { Hay que mencionar que también cuentan con RadioNet que es un radio } \\
\text { para tocar diferentes temas de esta red ciudadana. }\end{array}$ \\
\hline http://www.gracianet.org & $\begin{array}{l}\text { GraciaNet está orientada a los vecinos que viven en el barrio de Gràcia } \\
\text { de Barcelona, su comunicación se da principalmente a través de: } \\
\text { foros de discusión }\end{array}$ \\
\hline
\end{tabular}




\begin{tabular}{|c|c|}
\hline & $\begin{array}{ll}\text { - } & \text { noticias } \\
\text { - } & \text { listas de distribución }\end{array}$ \\
\hline http://www.noubarris.net & $\begin{array}{l}\text { NouBarrise está orientada a los vecinos del Barrio de NouBarris de } \\
\text { Barcelona, su comunicación se da principalmente a través de: } \\
\text { 1. foros de discusión } \\
\text { 2. chat } \\
\text { 3. listas de distribución }\end{array}$ \\
\hline
\end{tabular}

\section{Características de las Comunidades Virtuales}

Los miembros se sienten parte de una totalidad social amplia. Existe una red de relaciones entre sus miembros. Hay una corriente de intercambio de contenidos que tienen valor para sus miembros. Las relaciones entre los miembros se mantienen en el tiempo.

\section{Responden a necesidades:}

- un interés u objetivo común con otras personas;

- el deseo de compartir una experiencia o establecer relaciones sociales, profesionales o comerciales;

- el deseo de disfrutar de experiencias gratificantes;

- la necesidad de realizar transacciones de diversa índole.

\section{Dinámica de las Comunidades Virtuales}

La dinámica de las comunidades virtuales está orientada de acuerdo al principio del beneficio creciente, tanto para quien la crea y la administra como para sus miembros o usuarios y este se produce en la forma de un espiral acumulativo creciente.

Como punto de partida, un contenido interesante atrae miembros a la comunidad, lo cual genera a su vez más contenidos producidos por sus miembros, que a su vez hacen más atractivo el contenido.

Al mismo tiempo, los miembros perciben entonces un mayor valor en la comunidad lo cual promueve mayor y mejor interacción entre ellos, creando una mayor lealtad hacia la comunidad y una mayor permanencia de los usuarios en ella.

Una mayor lealtad promueve aún más la interacción entre sus miembros, pues se sienten más identificados con la comunidad y con los otros miembros, lo cual crea más valor y más lealtad.

La participación creciente de los miembros y la interacción entre ellos genera una información cada vez más completa sobre los miembros de la comunidad y su perfil de preferencias, intereses y puntos de vista, es decir, el perfil de sus pensamientos, sentimientos y acciones.

El valor percibido de la comunidad, atrae a usuarios externos y a administradores de otras comunidades, lo cual estimula la realización de transacciones diversas entre los miembros y entre los miembros de la comunidad de referencia y los de otras comunidades.

\section{Soluciones y Prestaciones para crear una Comunidad Virtual}

A la hora de abordar el proceso de creación de una comunidad virtual disponemos de diversas opciones que veremos a continuación y que podemos clasificar en 3 grupos

- Alternativas gratuitas o de bajo coste

- Alternativas de Software libre

- Alternativas de pago 
Veamos cada una de ellas por partes:

\section{Alternativas de bajo coste}

Son económicas, rápidas y muy sencillas de utilizar, nos lo dan todo preparado para empezar a trabajar, un dominio, el servicio de hospedaje y la comunidad virtual lista para ser creada, pero a cambio el servicio no es de muy alta calidad, tienen publicidad o tienen el riesgo de desaparecer.

\section{Yahoo Groups}

\section{http://grupos.yahoo.es}

Es un sistema de creación de comunidades virtuales en el que de forma gratuita podemos disponer de una página en muy poco tiempo, destacamos las siguientes características:

- Nuestra comunidad puede salir publicada en el directorio yahoo y ser localizada

- Está disponible en español

- Las secciones están predefinidas de inicio y no se pueden modificar (ni añadir ni quitar)

- La dirección es del tipo http://groups.yahoo.com/group/comunidad

- Incluye $20 \mathrm{Mb}$. de espacio para archivos

- El servicio es gratuito

- No se puede ampliar el espacio

\section{MSN Groups}

\section{http://groups.msn.com}

Es un sistema similar a Yahoo pero más actualizado y completo, su manejo es igual de sencillo, destacando:

- Nuestra comunidad puede ser publicada en el directorio de grupos MSN y ser localizada

- Está en español

- Las secciones se pueden modificar, añadir y eliminar a nuestra conveniencia de forma fácil y clara.

- La dirección es del tipo http://groups.msn.com/comunidad

- Incluye $3 \mathrm{Mb}$ de espacio

- El servicio es gratuito

- Se puede ampliar el espacio a $30 \mathrm{Mb}$ por una cuota anual

\section{Google Groups}

http://groups.google.com

A diferencia de los anteriores, en este caso el servicio ofrecido está más enfocado a comunidades que reciben la información a través de correo electrónico, teniendo solo la opción en la página de la comunidad de poder publica mensajes y comentarlos. Destaca:

- Nuestra comunidad puede ser publicada en el directorio de grupos Google y ser localizada

- Está en español

- Las secciones no se pueden modificar, solo hay lista de correo y foro

- La dirección es del tipo http://groups.google.com/group/comunidad

- El espacio es ilimitado

- El servicio es gratuito

\section{Elistas}

\section{http://www.elistas.com}

En este caso, este sistema se ofrece enfocado a los servicios de listas de correo, pero al crearla se dispone también de una página web para la comunidad, podemos ver que: 
- Nuestra comunidad puede salir publicada en el directorio elistas y ser localizada

- Está disponible en español

- Las secciones están predefinidas de inicio y no se pueden modificar (ni añadir ni quitar)

- La dirección es del tipo http://www.elistas.com/list/comunidad

- Incluye $10 \mathrm{Mb}$ de espacio para ficheros, 100 para mensajes

- El servicio es gratuito

- Se puede ampliar el espacio hasta $1 \mathrm{~Gb}$ en mensajes y 200 megas en archivos

\section{Alternativas de software libre}

Otra opción muy interesante es la de emplear plataformas de software libre para realizar el desarrollo de la comunidad nosotros mismos.

En este caso tendremos que disponer de un servicio de hospedaje y un dominio para poder alojar la comunidad virtual que realicemos y seremos nosotros los que tocaremos y desarrollaremos el código fuente del sistema lo que nos permitirá un sinfín de opciones, pero implica mayor tiempo de desarrollo

Hay varias tecnologías en el mercado para el desarrollo web que podemos emplear y en muchas de ellas, programadores han realizado anteriormente código para crear comunidades virtuales y lo comparten con el resto de forma gratuita, esta podría ser la base de nuestro desarrollo. Un lugar de referencia obligada para consultar es www.opensourcecms.com donde podremos encontrar varias de las opciones disponibles. Indicamos a continuación algunas direcciones destacadas de dichas plataformas.

\section{ASP (Clásico) \\ o MaxWebPortal \\ - http://www.maxwebportal.com \\ - Sistema para crear una comunidad muy completa en ASP de forma sencilla y fácil, con gestor de imágenes, foros, encuestas, noticias, muy recomendable para utilizar.}

\section{o ASP Nuke}

- http://www.aspnuke.com

- Surge a partir del conocido PHP Nuke para los desarrolladores de Active Server Pages, dispone de foros, encuestas y tablones de mensajes. Queda detenida con la aparición de .NET

\section{- ASP.NET}

o DotNetNuke

- http://www.dotnetnuke.com/

- Siguiendo la filosofía de PHP Nuke se crea este sistema completamente en .NET con muchísimos módulos personalizables y capaz de gestionar contenido propio. Dispone de registro de usuarios, calendario de eventos, personalización por skins, enlace con PayPal, listas de correo, etc. es la mejor opción de esta plataforma y de las mejores del mercado. Dispone de un libro de la prestigiosa editorial Wrox "Professional DotNetNuke ASP.NET Portals"

\section{o Community Starter Kit}

- http://www.asp.net/StarterKits/DownloadCommunity.aspx

- Kit de la plataforma .NET promovida por Microsoft para aprendizaje, código muy bien organizado e ideal para iniciarse. 


\section{- $\quad$ LAMP (LINUXIAPACHE/MySQL/PHP) \\ o PHP Nuke \\ - http://www.phpnuke.org \\ - Es el primer proyecto de este tipo de plataformas y sigue siendo una referencia para comparar, constantemente tiene actualizaciones y es la opción recomendad para introducirse debido a la cantidad de documentación de que se dispone.}

O PHPBB

- http://www.phpbb.com

- Se ha convertido en el sistema de facto para la creación de comunidades virtuales robustas cuya base sean los foros de conversación debido a su exclusiva dedicación, permite gestionar usuarios, moderar los foros y envío de e-mails a los participantes.

o TikiTwiki

- http://www.tikiwiki.org

- Este sistema para crear comunidades nos permitirá crear un portal completamente equipado, en español y con muchos módulos interesantes como galería de imágenes, gestor de archivos, enlaces recomendados, faq's, gestor de banners, creación de páginas propias, publicación de artículos y encuestas entre otros para la comunidad y calendario, tareas, archivos, mensajes, editor de textos y otras funcionalidades para cada usuario. Un completo portal para crear comunidades virtuales.

0

\section{GuppY}

- www.freeguppy.org

- Este sistema ofrece una funcionalidad similar al anterior pero está pensado para comunidades de poca escala o tamaño y para administradores con pocos conocimientos de programación. No utiliza base de datos por lo que su configuración es mucho más sencilla, dispone de diversos módulos para crear una comunidad y es la opción recomendad para introducirse en el mundo de las comunidades virtuales de software libre.

\section{- Mambo Server}

- http://www.mamboserver.com

- Se ha convertido en uno de los sistemas más empleados debido a su robustez, combinada con funcionalidad e instalación. Recomendado para la creación de portales de tamaño medio y con cierto nivel de personalización. En la celebración del evento LinuxWorld 2005 quedo en primera posición en el premio "Best open source solution" superando aplicaciones como Firefox. Actualmente lleva más de 3 millones de descargas.

- http://www.egroupware.org

- Para comunidades cuya base sea el trabajo y la colaboración virtual, este sistema pone a su alcance todas las funcionalidades necesarias como agenda compartida, calendario de eventos, gestor de proyectos, gestor de consultas de soporte, etc. Un sistema completo, privado para grupos de trabajo completamente funcional.

- http://www.spip.net/es

- La especial característica de este sistema es que es un gestor de contenidos para creación de portales en el que intervienen varios redactores. Esta pensado para que se puedan crear sitios completos desde una base mínima y que sean administrados por varios usuarios, 
creando una comunidad de administradores. Los visitantes verán el sitio web resultante pero los administradores disponen de uno de los mejores sistemas de software libre para la creación profesional de contenidos. Hay muchísima documentación para su instalación y abundantes foros en la red sobre su uso.

\section{Alternativas de pago}

Podemos encontrar de dos tipos diferentes, las que nos ofrecen como en el caso de las gratuitas en las que el coste que repercuten es una cuota y nosotros disfrutamos del servicio pero tenemos ni el código ni el control sobre el dominio o bien, aplicaciones como las de software libre que nos permiten instalar la aplicación en un servidor y disponer del control del código fuente para posibles modificaciones o mejoras:

\section{ASP (Aplication Service Provider)}

Aplicaciones en alquiler por las que se paga una cuota por su uso:

- MSN GROUPS

O http://groups.msn.com

- Elistas

o http://www.elistas.com

- $\quad$ WowBB (PHP)

o http://www.wowbb.com

o Aplicación en PHP que puede alquilarse y configurarse en modo ASP de forma que no tenemos que contratar el servicio de alojamiento, es la solución más sencilla de implementar, pues solo realizamos la gestión del contenido a cambio de una cuota. También disponen de la opción de comprar el código o pagar una licencia anual para alojarlo en otro servidor.

\section{Software a la venta de Comunidades virtuales para instalación propia}

\section{- $\quad$ CommunityServer (ASP.NET)}

o http://communityserver.org

- Completo sistema para creación de comunidades virtuales con soporte, que en versión de pago ofrece servicios adicionales y quita las restricciones impuestas por la licencia de modo gratuito, permitiendo su disposición del código y empleo con fines comerciales.

\section{- Communico Server (Cold Fusion)}

o http://www.communicoserver.com

o Este sistema permite la creación de cv's para emplear en entorno profesional, con gestor de mensajes internos, fotografías, e-mail, novedades, agenda, etc. Una opción muy recomendable para utilizar con esta plataforma de desarrollo de pago. 